\title{
Lazer Kesim Makinası Köprü Sisteminin Sayısal Dinamik Analizi
}

\author{
${ }^{* 1}$ Recep Y1lmaz, ${ }^{2}$ Ahmet Samanc1 \\ ${ }^{* 1}$ Tübitak UME, Ulusal Metroloji Enstitüsü, Gebze-Kocaeli, Türkiye \\ ${ }^{2}$ Mühendislik ve Mimarlık Fakültesi, Enerji Sistemleri Mühendisliği Bölümü Necmettin Erbakan Üniversitesi, \\ Türkiye
}

\section{Özet}

Mühendislik problemlerinin çözümünde kullanılan yöntemler analitik, sayısal ve deneysel olmak üzere üç ana kısımdan oluşmaktadır. Mühendislik uygulamalarında, genel olarak Elastisite teorisine dayalı olan analitik çözümlerin zor veya imkânsız olduğu gibi durumlarda, sonlu eleman, sınır eleman, sonlu farklar gibi sayısal çözüm teknikleri sıklıkla kullanılmaktadır. Bu çalışmada ürün tasarım ve optimizasyon işlemlerinin deneysel deneme yanılmalara maruz kalmadan sayısal ortamda gerçekleştirilmesi ile üretim maliyetlerinin çok önemli bir kısmının ve fazladan harcanan zamanın önüne geçilerek tasarım için en uygun parametreler belirlenmek istenmiştir. Bu kapsamda Solidworks Premium Edition programı ile tasarlanan lazer kesim makinasına ait köprü sisteminin CAD (Bilgisayar Destekli Çizim) modelinin yine Solidworks Simulation Premium programı ile dinamik analizi gerçekleștirilmiş ve sistemin maksimum stres durumuna maruz kaldığı nokta ve konum belirlenmiștir. Bu çalıșma ayrıca nihai tasarım için bir altyapı sağlaması ve sunduğu veriler doğrultusunda topolojik optimizasyon çalışmaları gerçekleştirilebilmesi açısından önem teşkil etmektedir.

Anahtar Kelimeler: Sonlu elemanlar, Dinamik analiz, Lazer kesim makinas1

\begin{abstract}
The methods used for solving engineering problems are composed of three main parts; analytical, numerical and experimental. Numerical solution techniques such as finite element, boundary element and finite difference are frequently used in engineering applications where analytical solutions based on elasticity theory in general are difficult or impossible. In this study, it is desired to determine the most suitable parameters for the design by avoiding a significant part of the production costs and the extra time, by carrying out the product design and optimization processes in the digital environment without experiencing experimental trial and error. In this context, the dynamic analysis of the bridge system for the laser cutting machine designed with Solidworks Premium Edition program with the Solidworks Simulation Premium program of the CAD (Computer Aided Drawing) model was performed and the point and the position where the system was exposed to the maximum stress condition were determined. This study is also important in that it provides an infrastructure for the final design and that topological optimization studies can be carried out in the direction of the given data.
\end{abstract}

Key words: Finite Element, Dynamic Analysis, Laser Cutting Machine

*Sorumlu Yazar: Adres: Tübitak UME, Ulusal Metroloji Enstitüsü, Gebze-Kocaeli, Türkiye. E-mail adres: yilmaz.recep@tubitak.gov.tr, Telefon:+902626795000 


\section{Giriş}

Lazer 1şını; karbondioksit lazer tezgâhlarında, karbondioksit gazına elektrik akımı verilerek oluşturulur. Lazer sac kesim, elde edilen lazer ışını ile çeşitli tezgâhlarda levha halindeki sacların istenilen şekil veya resme göre cnc kontrollü olarak kesilmesi işlemidir. Lazer teknolojisindeki gelişmeler, bu teknolojinin, alternatiflerini geride bırakarak, birçok endüstriyel alana uygulanabilmesine imkân tanımıştır. Lazer teknolojisinin sanayideki en büyük uygulama alanlarından birisi metal ve metal olmayan malzemeleri kesme işlemleridir. Lazerle kesim işleminde mekanik kesme kuvvetleri oluşmadığı için titreşimsiz ve hızlı bir operasyon yapılabilmektedir. Lazer teknolojisi ile yapılan metal kesim işlemleri geleneksel yöntemlere kıyasla birçok açıdan daha başarılı sonuçlar ortaya koymaktadır. Lazer sac kesim teknolojisiyle malzemede deformasyon en aza indirilir, parçada minimum pürüz ve çapaksız kesim sağlanır, çok küçük çaplarda delik delinebilir, herhangi bir mekanik gereç malzemeye temas etmediğinden malzemede ezilme veya çarpılma olmaz. Bu yüzden Dünyada ve ülkemizde pek çok alanda bu teknoloji uygulanmaktadır. Şekil 1'de örnek bir lazer kesim makinası gösterilmiştir. Hali hazırda ülkemizde de üretimi gerçekleştirilmekte olan lazer kesim makinalarının uluslararası muadilleri ile rekabet edebilmesi için gerekli olan teknik altyapı ancak yerinde mühendislik analizleri ve uygulamaları ile sağlanabilmektedir. Bu kapsamda lazer kesim kafası ve ekipmanlarını taşıyan köprü sisteminin hafifliği ve rijitliği büyük önem arz etmektedir. Bu da mühendislik bakış açısı ile yaklaşıldığı zaman tasarım maliyetlerini minimuma indirebilmek için bir takım sayısal analiz yöntemleri ile gerçekleştirilmektedir.

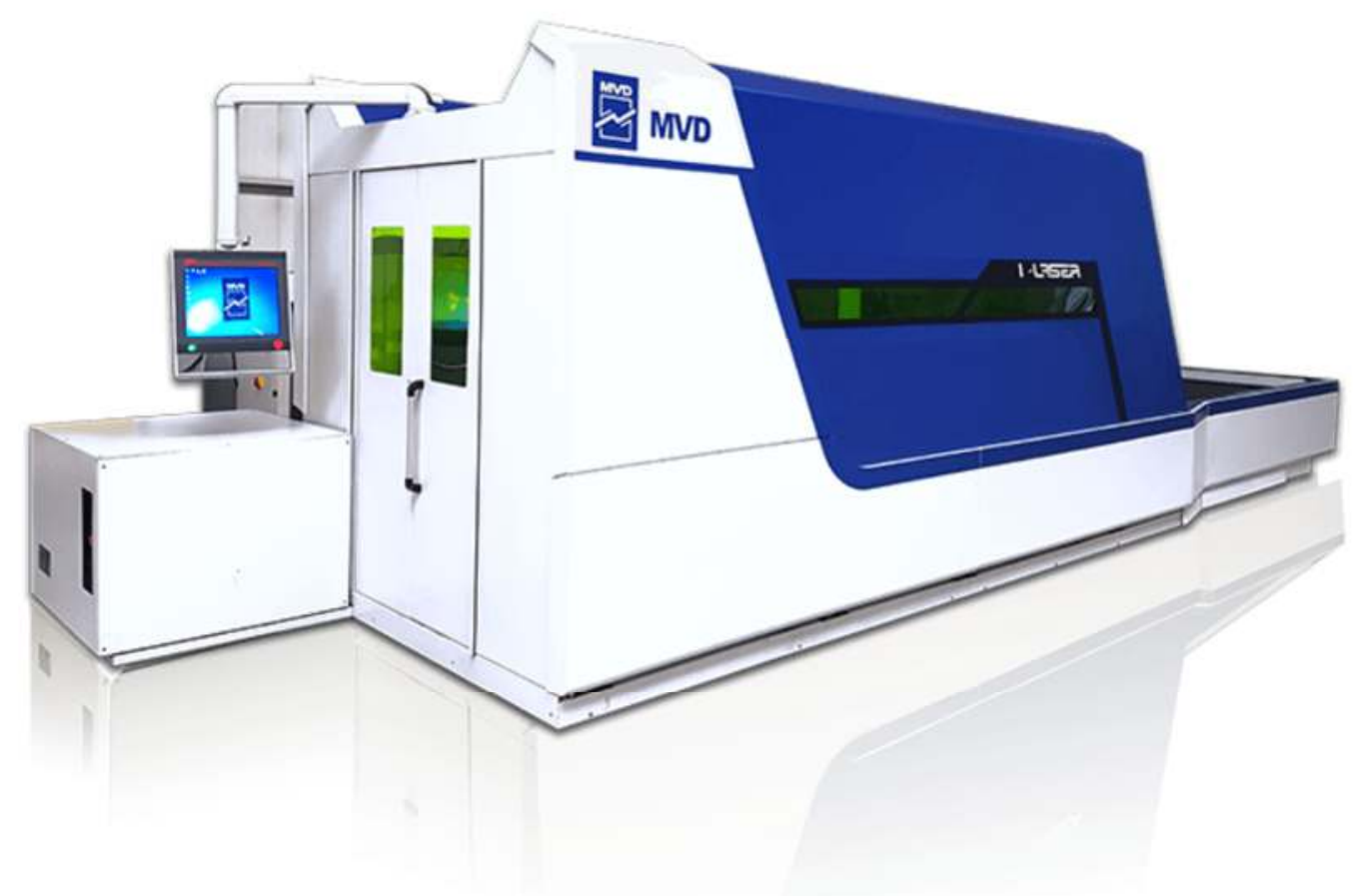

Şekil 1. Lazer kesim makinası 


\section{Köprü Sisteminin Sayısal Dinamik Analizi}

Üretim maliyetlerinin önemli bir oranı dolaylı olarak ürün tasarımı ve optimizasyonu işlemlerinin doğruluğu ve güvenilirliğine bağlıdır. Tasarımcının sadece bilgi ve tecrübesine dayalı olarak gerçekleştirilen üretimler ile yapının maksimum ve minimum ulaşabileceği sınırlar bilinmemekle birlikte üretim maliyeti de güvenlik faktörüne bağlı olarak ciddi şekilde arttırılmaktadır. Son yüzyıl ile birlikte bilgisayarların ve sonlu elemanlar yöntemi gibi sayısal optimizasyon tekniklerinin yapısal tasarımda kullanılmaya başlanılmasıyla beraber analitik olarak çözümü zor ve bazen imkânsız olan yapıda meydana gelen gerilmeler iyi bir yakınsama ile kolaylıkla tespit edilebilmektedir. Özellikle sayısal olarak kritik stres bölgeleri tespit edilip bu alanda deneysel çalışmalar yürütülmektedir. Bu da iş, zaman ve performans eğrilerini olumlu yönde etkilemektedir. Günümüzde de ürünlerin üretim maliyetlerinin kalite ve güvenlikten taviz vermeden minimum seviyeye indirilmesi özellikle dış pazarlarda rekabet noktasında çok önemli bir gereksinimdir. $\mathrm{Bu}$ gereksinim kapsamında doğrudan kalite ve maliyeti etkileyen ürün ağırlığının gelişmiş bilgisayarlar ile çeşitli sayısal analizleri gerçekleştirilerek minimize edilebilmesi başarılı bir tasarımın kilit noktasıdır. Bu kapsamda endüstride üretimi gerçekleştirilmekte olan lazer kesim makinelerinde kullanılan lazer kafası ve ekipmanları taşıyıcı köprü sisteminin, sistemi kontrol eden maksimum girdi değerleri ile uyum içinde sorunsuz çalışmasını sağlayacak optimizasyon çalışmalarına bir altyapı oluşturması açısından sayısal dinamik analizi gerçekleştirilecek ve deneysel deneme yanılma yöntemi ile kaybedilecek zaman ve mali kaybın önüne geçilecektir. Geliştirilecek olan proje ile kesim işleminde yüzeyde istenen kalite elde edilmiş olup, daha düzgün ve daha az enerjiyle çalışmalar gerçekleşecektir. Bu çalışmada kullanılacak olan lazer kesim makinası köprü sistemine ait CAD (Bilgisayar Destekli Çizim) modeli Şekil 2'de gösterilmiştir.

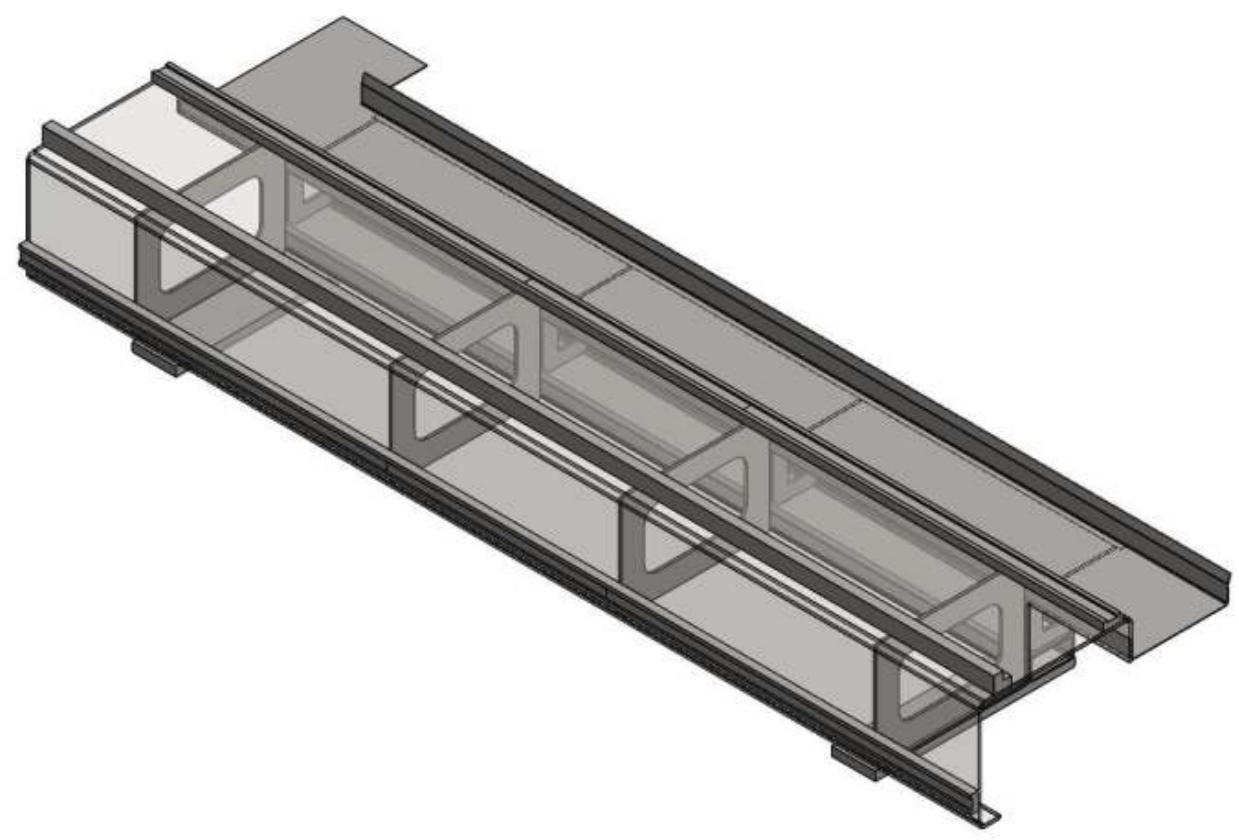

Şekil 2. Lazer kesim makinası köprü sistemi CAD tasarımı 
Planlanan topolojik optimizasyonu başarılı bir şekilde gerçekleştirebilmek için sistemin mekanik davranışının, kritik yük bölgelerinin ve yük dağılımının iyi tespit edilebilmesi gerekmektedir. Bu kapsamda ilk olarak SolidWorks programında üç boyutlu CAD modeli (Şekil 2) hazırlanan sistem yine bu programın Simulation Premium paketi ile dinamik analize tabi tutulacaktır. Analiz parametreleri belirlenirken ivmenin lineer bir şekilde artması ve azalması sağlanacaktır. Dinamik analiz sonuçlarına göre gerilmenin en yoğun olduğu zaman adımı statik olarak simüle edilerek daha hassas sonuçlar aranacaktır. Sonuç grafiklerinden gerilme ve deformasyon verileri yorumlanarak lazer köprüsü sistemine ait veriler iyi bir karşılaştırma için elde edilmiş olacaktır. Hazırlanan dinamik analize ait etüt özellikleri aşağıda verilmiştir.

Etüt adı $\quad$ : Lazer Makinası Köprü Sistemi Dinamik Analizi

Analiz tipi : Doğrusal Olmayan - Dinamik

Mesh tipi : Kat1 Mesh

Başlangıç zamanı : :0 Saniye

Bitiş zamanı : : 0.585 Saniye

Zaman artışı : Otomatik adımlama

Büyük yer değiştirme : Açık

Termal Etki : Açık

Termal seçenek : Sicaklık yüklerini ekle

Sifir gerilim sıcaklığ $: 298$ Kelvin

Çözümleyici tipi : Büyük Problem Doğrudan Seyrek

Kontrol tekniği : Kuvvet

Yineleme tekniği : NR (Newton-Raphson)

Entegrasyon Yöntemi : Newmark

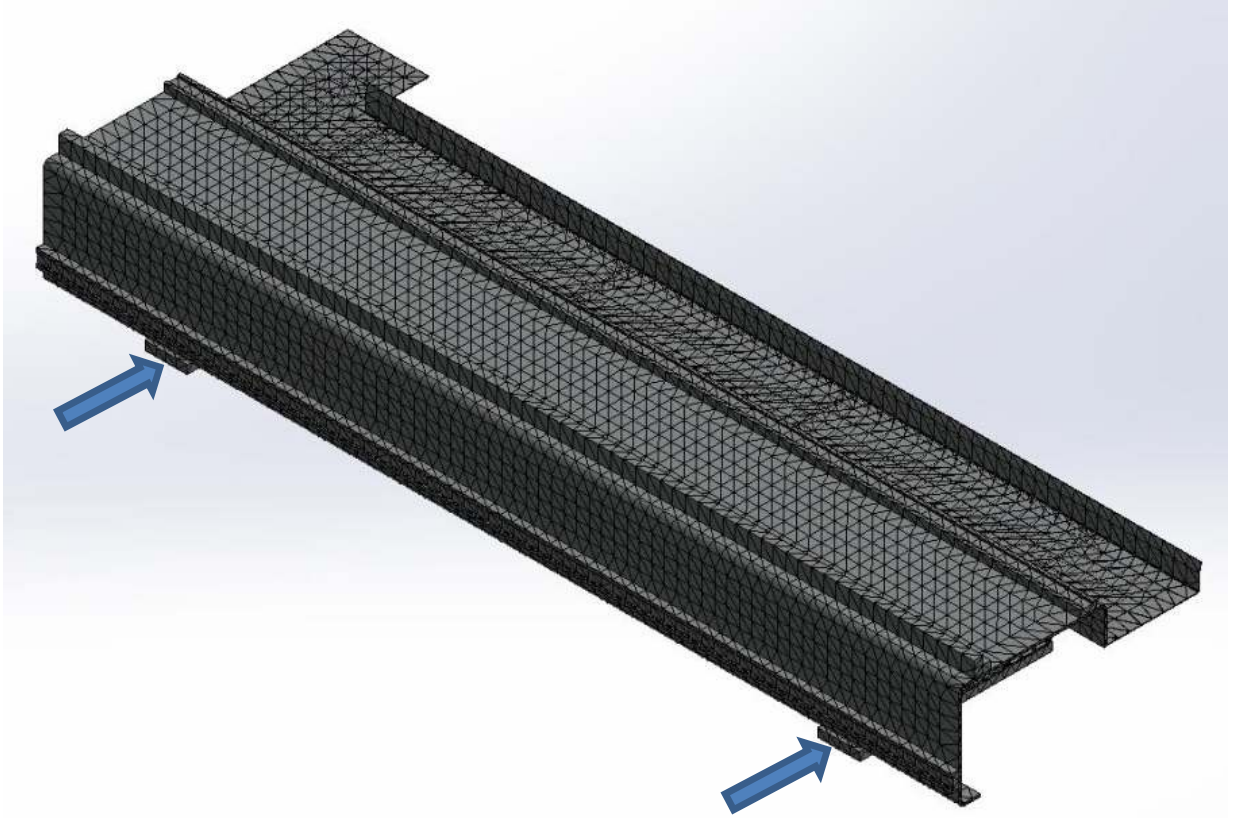

Şekil 3. Köprü sisteminin mesh işlemi gerçekleştirilmiş hali 
Köprü sistemi dinamik analizi için lineer olarak artan $22 \mathrm{~m} / \mathrm{s}^{2}$ (yaklaş1k 2,2 g) ivmeli bir hareket modellenmiştir. İvmeli hareketi takiben $2 \mathrm{~m} / \mathrm{s}$ sabit hız ile bir süre devam eden köprü sistemi yine lineer olarak yavaşlama hareketi yapmakta ve çok kısa bir süre için geri dönüş yapmaktadır. Bunun sebebi sisteme etki eden maksimum kuvveti hesaplayabilmektir. Sistemin gidiş ve dönüş için harcadığ1 toplam süre 0,585 saniyedir. Analiz için akma mukavemeti $235 \mathrm{MPa}$ olan St-37 çeliği dikdörtgen profil kullanılmıştır. Mesh işlemi için 76900 düğüm noktası ve 39195 eleman kullanılarak elde edilen model Şekil 3'te gösterilmiştir. Ayrıca Şekil 3'teki oklarla belirtilen kısımlardan sistem için fikstür tanımlanmış olup lineer ivmeli hareket bu kısımlardan ok yönünde verilmiştir. Sistemin dinamik analiz boyunca metre cinsinden izleyeceği yolu gösteren yol - zaman grafiği Şekil 4'te verilmiştir.

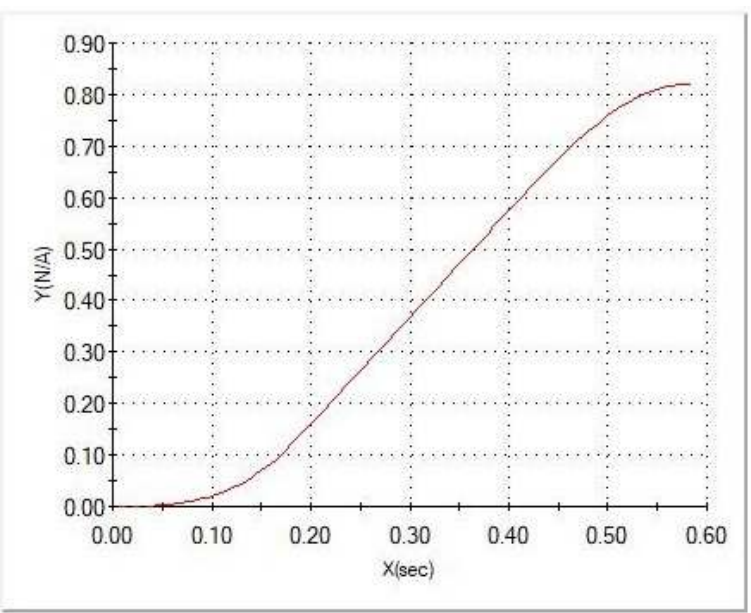

Şekil 4. Yol - Zaman grafiği

\section{Dinamik Analiz Sonuçları}

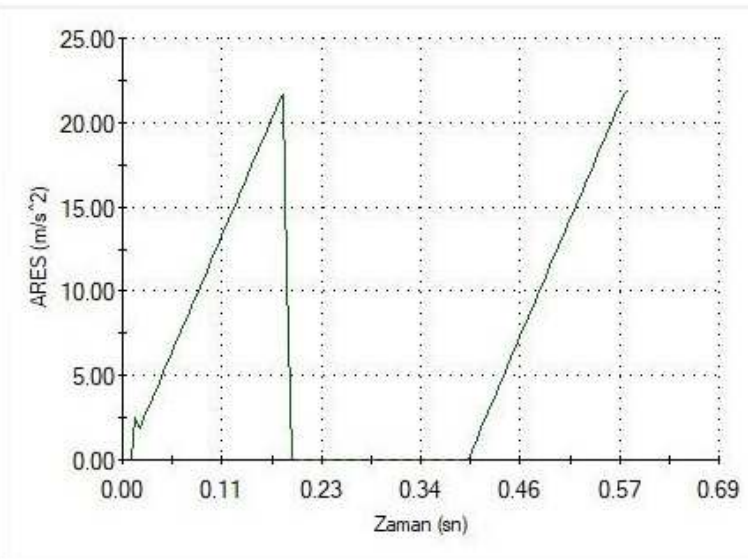

Şekil 5. İvme - Zaman grafiği

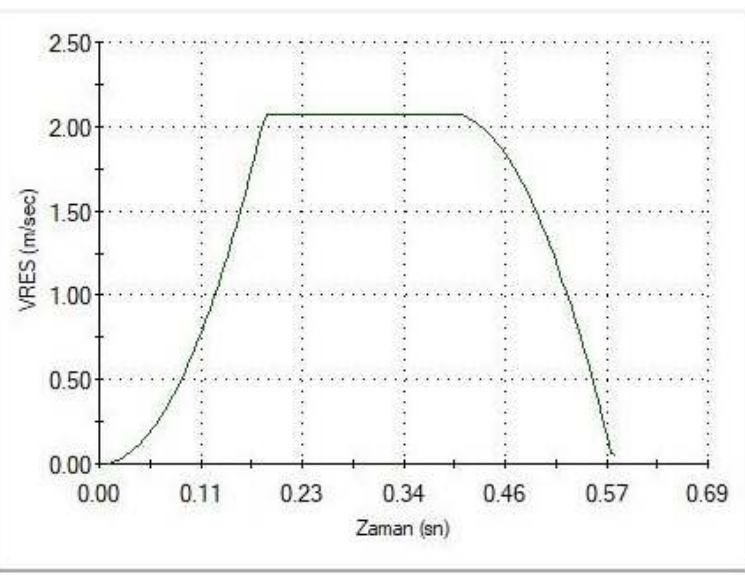

Şekil 6. Hız - Zaman grafiği

Şekil 5'te gerçekleştirilen dinamik analize ait ivme - zaman grafiği verilmiştir. İvme yaklaşık 0,2 saniye boyunca lineer olarak artmakta sonra sıfır değerine inmekte ve dönüş hareketi için tekrar 0,2 saniye boyunca lineer artış göstermektedir. Şekil 6'da ise analize ait hız - zaman grafiği 
verilmiş olup yaklaşık 0,2 saniye boyunca sistemin 0 - $2 \mathrm{~m} / \mathrm{s}$ hıza ulaştığı görülmekte ve bir süre sabit hızla hareket eden sistemin durma hareketi için yavaşladığı anlaşılmaktadır.

Şekil 7'de ise dinamik analizi gerçekleştirilen taşıyıcı köprü sisteme ait sabit hızdaki hareketin olduğu bir andaki gerilme durumu verilmiştir. Grafikte görüldüğü üzere $2 \mathrm{~m} / \mathrm{s}$ hizla sabit hareket eden sistemde maksimum gerilme lineer ivmeli hareketin verildiği kısımlara yakın olan bayraklara ait radyus bölgeleri üzerinde meydana gelmiştir.

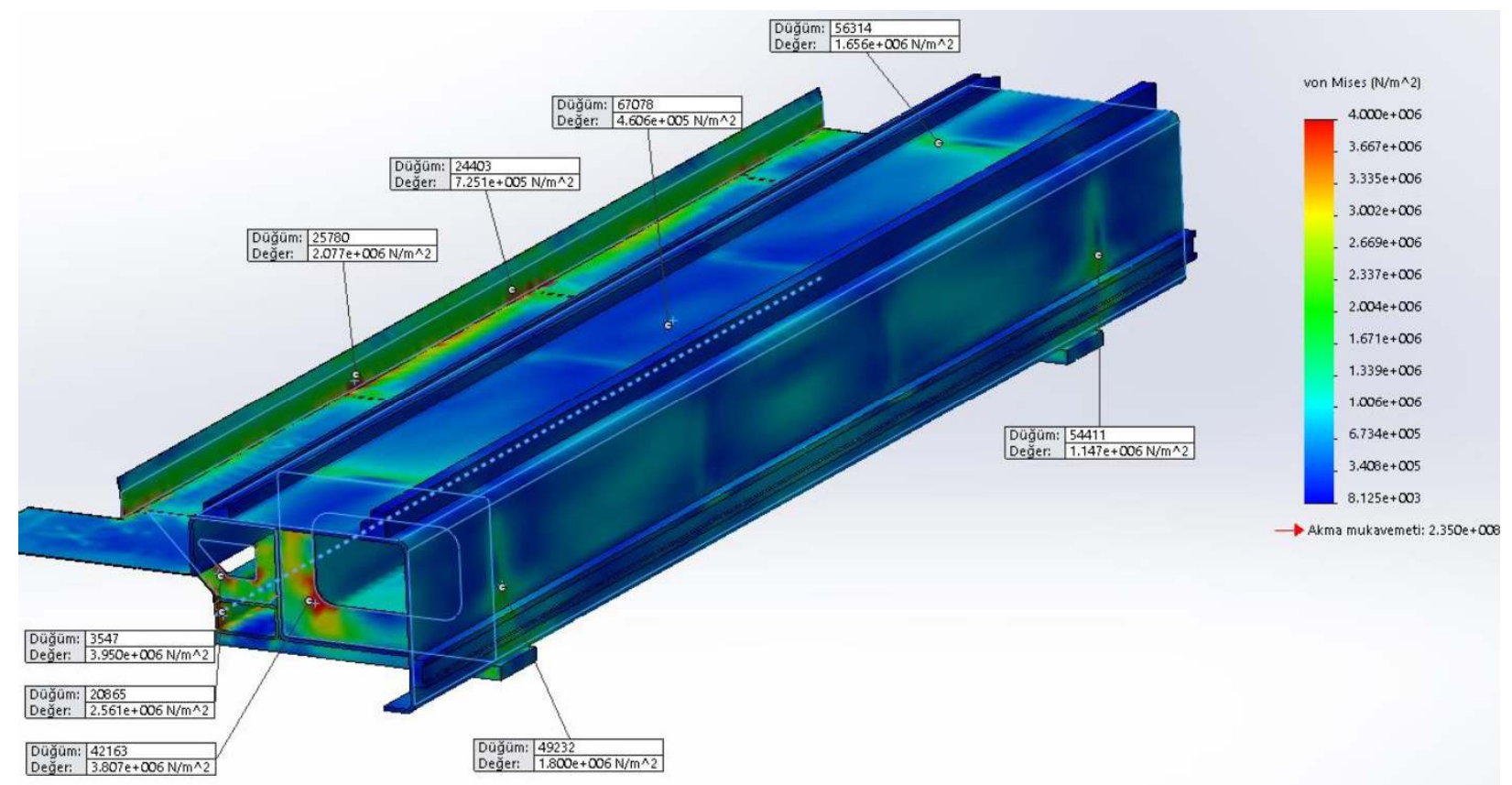

Şekil 7. Sabit hız ile yol alan alan sistemde meydana gelen gerilmeler
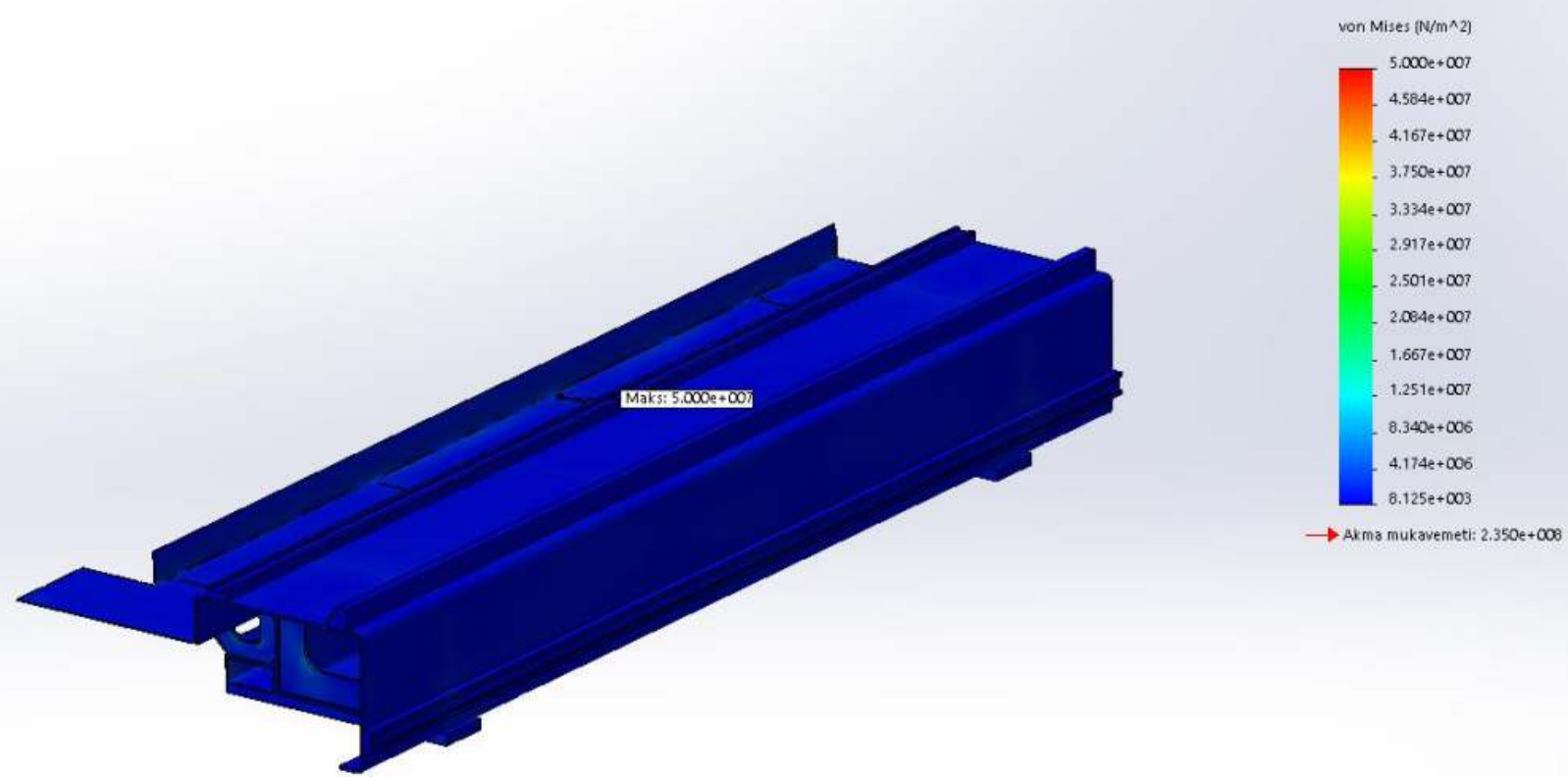

Şekil 8. Frenleme esnasında meydana gelen gerilmeler 


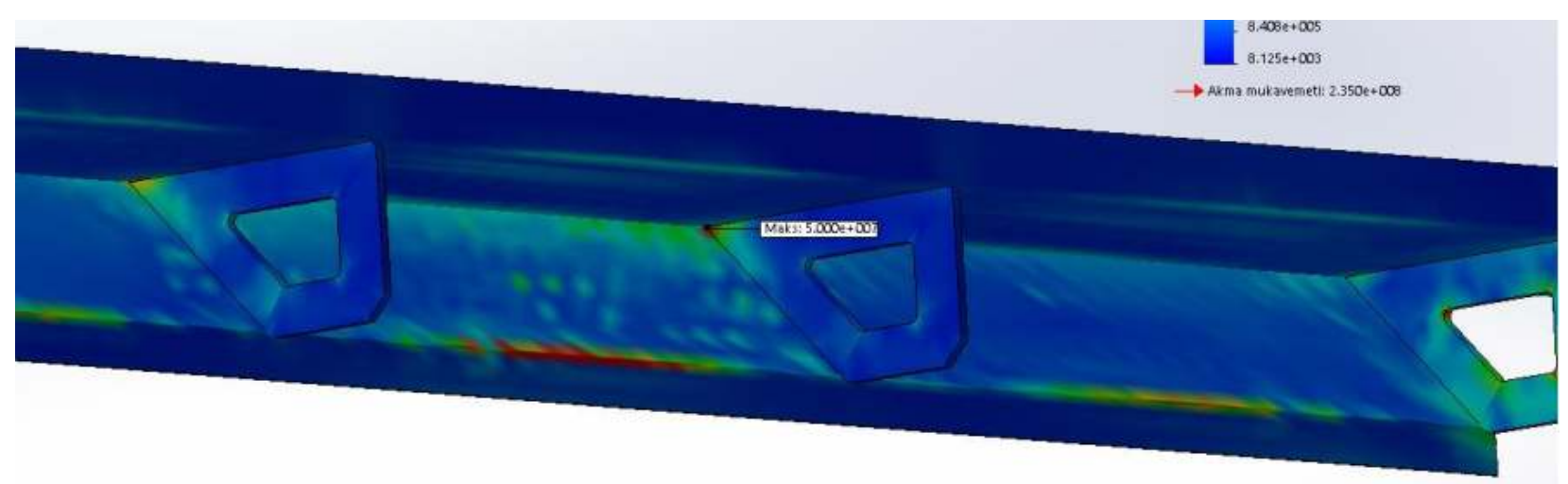

Şekil 9. Frenleme esnasında meydana gelen maksimum gerilme durumu

Şekil 8 ve Şekil 9'da sistemin frenleme yaptığı gerilmelerin en kritik olduğu anlardan birine ait maksimum gerilme değeri ve konumu verilmiştir. Burada maksimum gerilme değerinin $50 \mathrm{MPa}$ olduğu ve dikdörtgen profil dışında arka destek sisteminin birleşme noktasında gerçekleştiği görülmektedir.

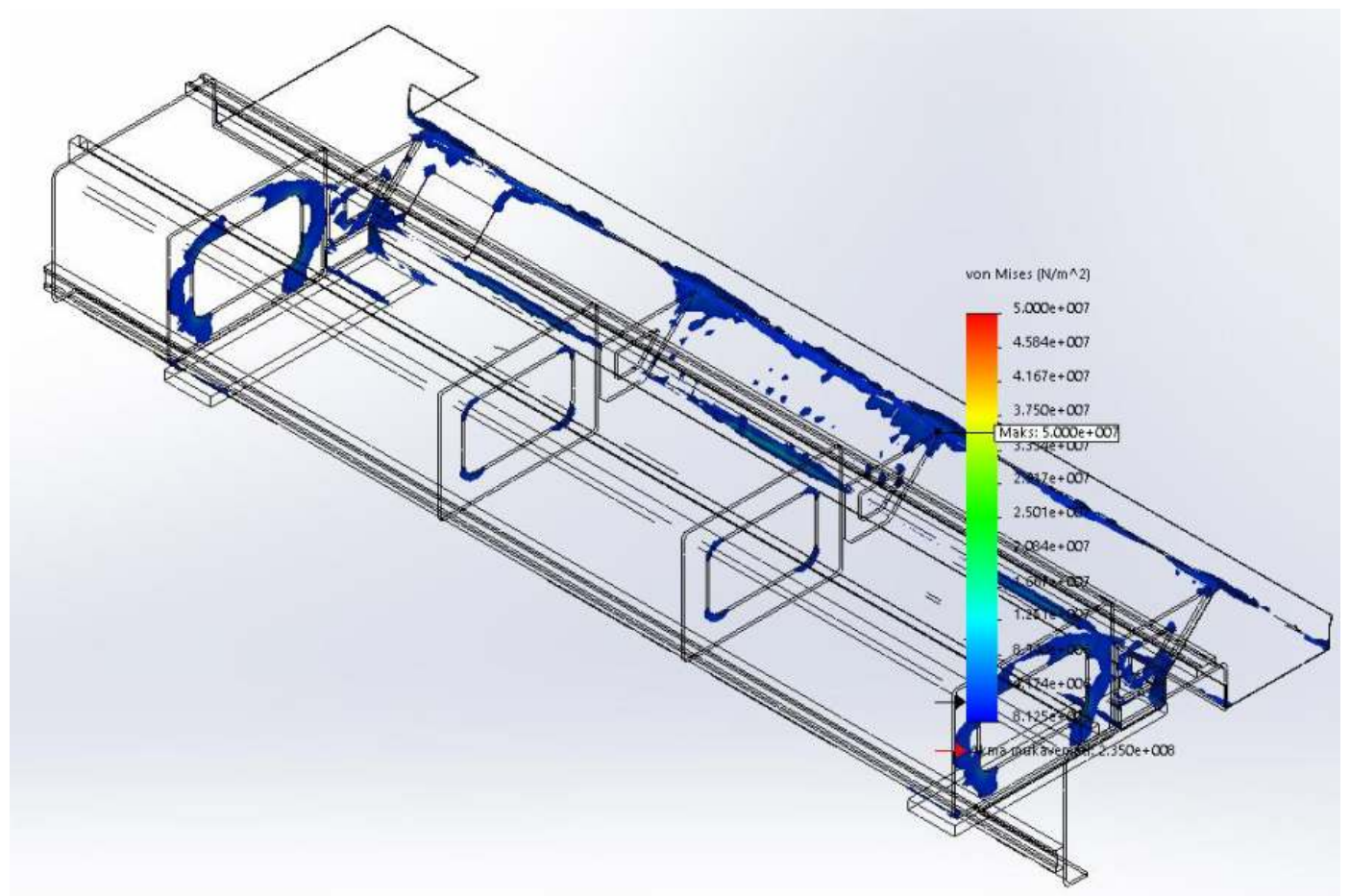

Şekil 10. Tasarım öngörü grafiği

Şekil 10'da ise tüm gerilmelerin maksimum olduğu anda köprü sistemine ait tasarım öngörü grafiği verilmiştir. Burada boyalı kısımlarda özellikle bayrak radyus bölgelerinde gerilmelerin daha fazla yoğunlaştığı görülmektedir. Bu grafik, köprü sistemi hafifletme çalışmaları için bir altyapı oluşturmaktadır. 


\section{Tartışma}

Elde edilen sonuçlara göre köprü sisteminin belirtilen parametrelere göre çalışma biçimi güvenlidir fakat optimizasyon açısından gerekli hafifletme çalışmaları yapılarak hız ve ivme değerlerinde artışa gidilebilir. Bu da lazer kesim hızını olumlu etkileyecek ve hassasiyette mevcut durum korunacaktır.

\section{Sonuç}

$\mathrm{Bu}$ çalışmada lazer kesim cihazlarında kullanılan lazer kafası ve ekipmanlarını taşıyıcı köprü sisteminin dinamik analiz çalışması gerçekleştirilerek sistemin mekanik davranışı incelenmek istenmiştir. Bu çalışma, sistemi kontrol eden maksimum girdi değerleri ile uyum içinde köprü sisteminin sorunsuz çalışmasını sağlayacak optimizasyon çalışmalarına bir altyapı oluşturması açısından önem arz etmektedir. Gerçekleştirilen analiz ile deneysel deneme yanılma yöntemi ile kaybedilecek zaman ve mali kaybın önüne geçilmesi amaçlanmıştır. Analiz sonucu elde edilen verilere göre, geometride bazı değişiklikler yapılarak hafifletme ve rijitlik çalışmaları gerçekleştirilecektir. Özellikle tasarım öngörü grafiğinden yola çıkılarak gerçekleştirilecek optimizasyon işlemlerinden sonra lazer ile kesim işlemi yapılan yüzeyde istenen kalite elde edilecek olup, daha düzgün ve daha az enerjiyle çalışmaların gerçekleştirilmesi sağlanacaktır.

\section{Kaynaklar}

[1] Swami B. M, Kumar K. S. R, Ramakrishna C. H. Design And Structural Analysis Of Cnc Vertical Milling Machine Bed. International Journal of Advanced Engineering Technology 2012; 3(4), 97-100.

[2] Parmar A. H, Zala K. P, Patel A. R. Design and modification of foremost element of hydraulic press machine. International Journal of Advanced Scientific and Technical Research 2014; 4.

[3] Karaoğlu S, Çiçek. Dip Klapesinin Ansys ${ }^{\circledR}$ İle Tasarım Optimizasyonu. Pamukkale Üniversitesi Mühendislik Bilimleri Dergisi 2008; 14(2), 155-160.

[4] Can İ. Palet Sisteminin Sonlu Elemanlar Metodu İle Mukavemet Analizinin Yapılması Ve Optimizasyonu (Doctoral dissertation, Fen Bilimleri Enstitüsü) 2015.

[5] Hızır O. G. Askeri Gemilerde Helikopter Güvertesinin Yapısal Ağırlık Optimizasyonu (Doctoral dissertation, Fen Bilimleri Enstitüsü) 2011.

[6] Yavuzcan H. G, Önder M, Keçel S, Akkurt A, Korkmaz M. S. Yatık Ağız Açma Ve Kalibre Etme Makinasının Yapısal Analizi Ve Ağırlık Optimizasyonu. Gazi Üniversitesi Fen Bilimleri Dergisi Part C: Tasarım ve Teknoloji 2015; 3(3), 555-564.

[7] http://www.mvd.com.tr; 2018. 